\title{
LETTER
}

\section{Continuous infusion of meropenem in critically ill patients: practical considerations}

\author{
Fabio Silvio Taccone* \\ See related research by Chytra et al., http://ccforum.com/content/16/3/R113
}

I read with interest the article from Chytra and colleagues, who investigated the effectiveness and safety of continuous infusion (CI) of meropenem compared with intermittent infusion (II) in a large cohort $(n=240)$ of critically ill patients [1]. They found that although clinical cure at the end of therapy was similar between the two strategies, microbiological success was higher in the CI group and was independently associated with continuous drug administration. CI was also associated with a shorter ICU stay, as well as shorter duration of therapy and a lower total dose of meropenem. This paper highlights the potential benefits of CI of $\beta$-lactams compared with standard administration in critically ill patients, which has already been suggested in previous retrospective studies [2]. Nevertheless, some points need to be discussed.

First, the doses of meropenem used by Chytra and colleagues could be largely criticized. The authors have already underlined how the CI strategy received a lower daily regimen than the bolus strategy ( 4 g/day vs. 6 g/day) and the use of such an approach showed only clinical equivalence with but not superiority to II in clinical trials [3]. More importantly, the II group was treated with higher than recommended daily regimens (2 g every 8 hours rather than 1 g every 8 hours). In severe sepsis and septic shock, a 1 g loading dose of meropenem resulted in optimal serum concentrations to treat pathogen with a minimal inhibitory concentration (MIC) of $2 \mu \mathrm{g} / \mathrm{ml}$ in $75 \%$ of patients, while it provided adequate drug levels for lower MICs in all patients [4]. The same results were shown for both loading and steady-state doses when serum and subcutaneous drug levels were measured [5]. Calculating the doses of meropenem on population pharmacokinetic models from patients without critically illness may thus underestimate antibiotic concentrations measured in real populations and result in unnecessarily high drug regimens. Future research should therefore consider standard drug regimens (1 g every 8 hours) as a valuable control for CI strategies in septic patients.

Second, the CI group received $4 \mathrm{~g}$ meropenem over 24 hours, aiming to reach $100 \%$ of the time that drug concentrations would be above the MIC ( $>$ MIC) for most Gram-negative pathogens. Nevertheless, carbapenems need only $40 \% \mathrm{~T}>\mathrm{MIC}$ to have bactericidal effects, because of the significant post-antibiotic effect and enhanced leucocyte activity shown in in vitro models [6]. As such, prolonging the infusion of meropenem over 3 hours between two administrations would be sufficient to maximize its antibacterial activity [3]. Clearly, further clinical investigations are needed to better identify the optimal $\mathrm{T}>\mathrm{MIC}$ to use when $\mathrm{CI}$ of $\beta$-lactams is given during life-threatening infections.

Third, because the median MIC of the pathogens was approximately $0.125 \mu \mathrm{g} / \mathrm{ml}$, it is difficult to understand how CI could result in higher clinical cure and bacteriological response rates when compared with II. In one study, CI of cefepime resulted in similar clinical outcome and bacterial eradication when compared with II in critically ill patients [7]; however, the effectiveness of drug concentrations at steady state was also similar between the two strategies because most of the isolated pathogens were highly susceptible to the study drug. On the contrary, CI of ceftazidime was associated with a greater clinical cure rate than II in patients with ventilatorassociated pneumonia, particularly for those infections caused by organisms with MIC $8 \mu \mathrm{g} / \mathrm{ml}$ [2]. A CI strategy may evidently result in better clinical outcome only when treating less susceptible strains, in which II is unable to achieve adequate $\mathrm{T}>\mathrm{MIC}$, and would not necessarily be more advantageous for all critically ill patients.
*Correspondence: ftaccone@ulb.ac.be

Department of Intensive Care, Laboratoire de Recherche Experimentale, Erasme Hospital, Route de Lennik, 808, 1070 Brussels, Belgium 


\section{Authors' response}

Ivan Chytra, Martin Stepan, Jan Benes, Petr Pelnar, Alexandra Zidkova, Tamara Bergerova, Richard Pradl and Eduard Kasal

We thank Dr Taccone for his interest in our article [1] and for his remarks. In general, we agree with most of them. We actually tried to address similar comments in the discussion of our article. Nevertheless, we would like to add a few remarks and clarifications.

First, when we designed and started the study (2007), the dose of meropenem ( $2 \mathrm{~g}$ every 8 hours) for intermittent administration was calculated according to the suggestion for achievement of the antibiotic's optimal probability of target attainment and cumulative fraction of response in critically ill patients with serious infections $[8,9]$. In view of the later published results from Taccone and colleagues [4] and owing to the low MIC of pathogens in our study, however, we retrospectively find the dose used ( 2 g every 8 hours) unnecessarily high.

Second, although in carbapenems the recommended minimum percentage of the dosing interval for $\mathrm{T}>\mathrm{MIC}$ is only $40 \%$, in patients with serious bacterial infections the achievement of $100 \% \mathrm{~T}>\mathrm{MIC}$ displayed a significantly greater clinical cure $(82 \%$ vs. $33 \%, P=0.002)$ and bacteriological eradication $(97 \%$ vs. $44 \%, P<0.001)[10,11]$. Maintaining antibiotic concentrations above the MIC for $100 \%$ of the dosing interval was thus used in our study.

Third, we agree with the statement that the efficacy of $\mathrm{CI}$ of $\beta$-lactams should be investigated in a population suffering from infections caused by less susceptible strains with elevated MICs (which we also pointed out in the conclusion to our article [1]).

To conclude, we concur with the comments of $\mathrm{Dr}$ Taccone and we originally strove to elucidate them in the discussion of our article [1]. Bearing in mind these new facts and information, we would respect them if designing the study in the present day.

\section{Abbreviations}

$\mathrm{Cl}$, continuous infusion; II, intermittent infusion; MIC, minimum inhibitory concentration; $\mathrm{T}>\mathrm{MIC}$, time above the minimum inhibitory concentration.

\section{Competing interests}

The authors declare that they have no competing interests.

Published: 27 August 2012

\section{References}

1. Chytra I, Stepan M, Benes J, Pelnar P, Zidkova A, Bergerova T, Pradl R, Kasal E: Clinical and microbiological efficacy of continuous versus intermittent application of meropenem in critically ill patients: a randomized openlabel controlled trial. Crit Care 2012, 16:R113.

2. Lorente L, Jiménez A, Palmero S, Jiménez JJ, Iribarren JL, Santana M, Martín MM, Mora ML: Comparison of clinical cure rates in adults with ventilatorassociated pneumonia treated with intravenous ceftazidime administered by continuous or intermittent infusion: a retrospective, nonrandomized, open-label, historical chart review. Clin Ther 2007 , 29:2433-2439.

3. Mohd Hafiz AA, Staatz CE, Kirkpatrick CM, Lipman J, Roberts JA: Continuous infusion vs. bolus dosing: implications for beta-lactam antibiotics. Minerva Anestesio/ 2012, 78:94-104

4. Taccone FS, Laterre PF, Dugernier T, Spapen H, Delattre I, Wittebole X, De Backer D, Layeux B, Wallemacq P, Vincent JL, Jacobs F: Insufficient $\beta$-lactam concentrations in the early phase of severe sepsis and septic shock. Crit Care 2010, 14:R126.

5. Roberts JA, Kirkpatrick CM, Roberts MS, Robertson TA, Dalley AJ, Lipman J: Meropenem dosing in critically ill patients with sepsis and without renal dysfunction: intermittent bolus versus continuous administration? Monte
Carlo dosing simulations and subcutaneous tissue distribution. J Antimicrob Chemother 2009, 64:142-150.

6. Novelli A, Fallani S, Cassetta MI, Conti S, Mazzei T: Postantibiotic leukocyte enhancement of meropenem against Gram-positive and Gram-negative strains. Antimicrob Agents Chemother 2000, 44:3174-3176.

7. Georges B, Conil JM, Cougot P, Decun JF, Archambaud M, Seguin T, Chabanon G, Virenque C, Houin G, Saivin S: Cefepime in critically ill patients: continuous infusion vs. an intermittent dosing regimen. Int J Clin Pharmacol Ther 2005, 43:360-369.

8. Ludwig E, Konkoly-Thege M, Kuti JL, Nicolau DP: Optimising antibiotic dosing regimens based on pharmacodynamic target attainment against Pseudomonas aeruginosa collected in Hungarian hospitals. Int J Antimicrob Agents 2006, 28:433-438.

9. Wang $\mathrm{H}$, Zhang B, Ni Y, Kuti JL, Chen B, Chen M, Nicolau DP. Pharmacodynamic target attainment of seven antimicrobials against Gram-negative bacteria collected from China in 2003 and 2004. Int J Antimicrob Agents 2007, 30:452-457.

10. Turnidge JD: The pharmacodynamics of beta-lactams. Clin Infect Dis 1998, 27:10-22.

11. MCKinnon PS, Paladino JA, Schentag JJ: Evaluation of area under the inhibitory curve (AUIC) and time above the minimum inhibitory concentration $(T>M I C)$ as predictors of outcome for cefepime and ceftazidime in serious bacterial infections. Int J Antimicrob Agents 2008, 31:345-351.

doi:10.1186/cc11459

Cite this article as: Taccone FS: Continuous infusion of meropenem in critically ill patients: practical considerations. Critical Care 2012, 16:444. 